\title{
The Reflective Model of
}

\section{Intercultural Competency:}

\section{A Multidimensional, Qualitative Approach to Study Abroad Assessment}

\author{
Tracy Rundstrom Williams \\ Texas Christian University
}

\section{Introduction}

Judging from the recent surge in research on outcomes assessment, many study abroad offices rely on quantitative surveys and measures to collect student outcomes data (Olson and Kroeger 2001, Ingraham and Peterson 2004, Chieffo and Griffiths 2004, Kehl and Morris 2007, Sutton and Rubin 2007). This paper presents a multidimensional, qualitative approach to data collection. This approach makes qualitative data easy to collect and encourages students to reflect and contextualize their experience, so that the students themselves articulate their own growth towards intercultural competence. This article will demonstrate how I established a set of learning outcomes for study abroad, encouraged student awareness of these learning outcomes prior to departure and during the program, and collected qualitative data to measure how well students were reaching these outcomes. This innovative approach, the Reflective Model of Intercultural Competence, shows both the benefits of qualitative data and of a multidimensional collection process. This approach provides rich data about student gains. It encourages students to consider their experience in broad terms, providing them with meaningful ways to articulate their experience to others. Furthermore, integrating learning outcomes into assessment reinforces their importance. The Reflective Model of Intercultural Competence provides a new and effective multifaceted tool for assessing study abroad outcomes.

\section{Establishing Learning Outcomes}

As part of a strategic planning process in 2006, the Center for International Studies: TCU Abroad decided it was important to determine the desired learning outcomes for our study abroad students. These outcomes were based on the desire for our students to develop intercultural competence, which can 
be defined as having three dimensions: the cognitive dimension (knowledge about cultural issues), the affective dimension (motivation or willingness to act in intercultural situations), and the behavioral dimension (skills and abilities related to intercultural situations) (Gudykunst, Ting-Toomey \& Wiseman 1991, Kim 1991, Grunzweig \& Rinehart 1998, Deardorff 2004).

The cognitive dimension refers to possessing knowledge about cultural norms, values, behaviors, and issues. Having appropriate knowledge of the country and culture and being open to new information and perspectives is commonly cited as important to intercultural competency (Gudykunst 1991, Kim 1991, Deardorff 2004, Jackson 2005).

The affective dimension (motivation or willingness to act in intercultural situations) relates to the flexibility to adapt to new situations and open-mindedness to encounter new values. Flexibility, adaptability, and ability to deal with stress and ambiguity are often noted as a necessity for intercultural competency (Dignes 1983, Gudykunst 1991, Brislin \& Yoshida, 1994, Kelley \& Meyers, 1995, Ting-Toomey 1999, Deardorff 2004, Jackson 2005). In addition, openmindedness, respect, and cross-cultural empathy are noted by many as important to intercultural competency (Dignes 1983, Gudykunst 1991, Brislin \& Yoshida, 1994, Kelley \& Meyers, 1995, Ting-Toomey 1999, Deardorff 2004).

Within the behavioral dimension, critical skills, such as resourcefulness, problem-solving skills, and culturally-appropriate people skills are relevant. Resourcefulness, self-reliance, creative thinking, analytical skills, behavioral adaptability and culturally appropriate social skills recur throughout intercultural communication competency research (Dignes 1983, Gudykunst 1991, Brislin \& Yoshida, 1994, Kelley \& Meyers, 1995, Ting-Toomey 1999, Deardorff 2004, Jackson 2005).

Table 1: Intercultural Competency

\begin{tabular}{|l|l|l|}
\hline Cognitive Dimension & Affective Dimension & Behavioral Dimension \\
\hline $\begin{array}{l}\text { Knowledge about } \\
\text { cultural norms, values, } \\
\text { behaviors, and issues }\end{array}$ & $\begin{array}{l}\text { Flexibility to adapt to } \\
\text { new situations } \\
\text { Open-mindedness to to } \\
\text { encounter to new } \\
\text { values }\end{array}$ & $\begin{array}{l}\text { Critical skills such as } \\
\text { resourcefulness, } \\
\text { problem-solving skills, } \\
\text { and culturally- } \\
\text { appropriate people skills }\end{array}$ \\
\hline
\end{tabular}

The Reflective Model of Intercultural Competency translates these three dimensions into the following desired learning outcomes for study abroad students:

Increased understanding of international \& cultural issues: gain knowledge of the world's peoples, economies, environments, and political 
and social systems, and their interdependence; gain understanding of culture, its values and norms, and differences between cultures.

Increased flexibility: develop flexibility and adaptability in new environments; develop comfort with people of diverse backgrounds.

Increased open-mindedness and curiosity: learn from challenges to values and beliefs; develop respect for self and others; understand value of cultural diversity; develop a sense of curiosity and discovery about others.

Enhanced critical skills: develop skills such as resourcefulness, creative thinking, problem-solving, decision-making, visualization, socialization, negotiation, leadership, and teamwork in cultural diverse settings.

\section{Developing Awareness of Learning Outcomes}

These learning outcomes are presented to students, faculty, staff, and parents through our website (http://www.studyabroad.tcu.edu/), throughout the predeparture process, and in other venues such as our photography contest and to the Student Code of Conduct. The pre-departure handbook states the student learning outcomes and discusses what kinds of situations students might expect and how they might respond. During orientation, students are asked to respond video clips and scenarios of intercultural interactions with suggestions for how to adapt, behave, react, and understand the situation. In addition, the learning outcome categories for the photo contest are indicated in announcements that the students receive prior to departure and while abroad, giving them a frame of reference for the cultural differences they will face. Finally, students acknowledge the following when they sign the Student Code of Conduct:

TCU international programs strive to incorporate intercultural learning. As a part of being abroad, life will be different. In particular, the following attitudes and behaviors are expected:

I understand that changes in housing, food, customary practices, transportation, and more will require flexibility and adaptability.

I understand that values and norms may be different, and I will be respectful of others and take advantage of opportunities to learn about those differences.

I understand that living in an unfamiliar city, communicating in a different setting or language, being away from family and familiar resources and 
more will require resourcefulness, problem-solving skills, people skills, and personal responsibility.

This multi-tiered awareness approach gives students a framework for cultural differences and a set of strategies for adapting before they go abroad.

\section{Data Collection}

After the students' experiences abroad, we collect information from students on their development of these outcomes by asking open-ended questions on end-of-program evaluations and by using the learning outcomes as the themes of the photo contest.

\section{Student Evaluations}

The primary method for eliciting information on student outcomes is the end of term evaluations. One to two weeks after the students' programs end, they are sent a link to a web-based survey. The survey tool allows students to submit their answers anonymously, while at the same time tracking which students have not yet responded, allowing us to send follow-up reminders to them. Some questions are marked as required, i.e., the survey may not be submitted without answering them.

The survey includes demographic questions that allow us to collect statistics on gender, academic major and previous travel, as well as program evaluation questions to to assess program quality. The survey then asks questions on our learning outcomes, in order to assess what students have gained from their experience. The 'required' questions are:

1. What aspects of the country or culture where you studied abroad do you understand better? For example, did your experience increase your understanding of the country's people, values, culture, economy, politics, society and/or environment? If yes, how? If no, why not?

2. Describe any situation(s) where you were required to develop tolerance, flexibility, and a positive attitude in order to adapt to the situation. What did you learn from the experience? Examples of situations may include changes in housing, diet, conversational style with others, customary practices, transportation, etc.

3. Describe any situation(s) where you believe your values were questioned. How did you handle the situation? Were you able to discuss differences while accepting the position of others? Examples may include criticisms about U.S. individualism and materialism, questions 
on U.S. political issues, complaints about U.S. habits and norms, stereotypes about U.S. behavior, etc.

4. Explain scenarios in which you were required to demonstrate resourcefulness, creativity or problem solving skills, or people skills. What life-long lessons, if any, did you learn? Examples may include getting lost, solving a particular problem, communicating in a foreign language, etc.

5. It is not unusual for students to claim that studying abroad changed their lives. Do you believe your life is different because of studying abroad? How? Do you want to continue traveling internationally? Work in another country? Write any comments below that you want to share that have not been addressed in the questions above.

We have used this methodology with summer study abroad students since summer 2006. For the summer 2006 group, 122 of the 222 students completed the survey, for a response rate of 55\%. For the summer 2007 group, 82 of the 194 students completed the survey, for a response rate of $42 \%$.

Results have found that at least $85 \%$ of responders reply positively to these questions, and at least $50 \%$ of responders expand on these questions with meaningful answers (beyond, yes or something similarly short). Some students speak in general terms (i.e., "The life in Europe is more laid back and slow paced. The focus is more on being happy in the moment not doing things in hopes those acts will bring future joys and riches, " Summer 2006 Spain student) while some tell specific stories, "I was talking to the bell boy about politics, and it really made me question what I believe," Summer 2006 Italy student), but the comments generally provide interesting insight into the students' experiences and growth.

The answers also provide an opportunity to tease out those students simply giving socially expected responses, which is a concern with quantitative analysis, from those showing more in-depth learning. For example, in comments such as "I developed a tolerance for using the smelly public transportation system and NO AIR CONDITIONING. It really made me appreciate the luxuries of home," ( Summer 2007 London student)—we see a student who believes he/she has developed tolerance, but who has not shown an understanding of the culture or been able to move away from judging according to his/her own cultural framework. 


\section{Photo Contest}

A second method for obtaining data on student outcomes is the Photo Contest, which the Center for International Studies sponsors every fall. All study abroad participants from the previous year are invited to participate, Students are informed of the contest and categories before studying abroad, and sent reminders of the contest while abroad.

As with the program evaluation questions, the categories for the photo contest are based upon our learning outcomes for study abroad. Not only does this reinforce the importance of the learning outcomes, but it also demonstrates how study abroad extends beyond tourist experiences, to involve understanding the country, learning about the host country's values, becoming flexible, accomplishing new goals, and essentially becoming a different person. We look for photos to demonstrate these exciting, engaging aspects of study abroad. Entrants must submit a short explanation of how the photo demonstrates one of these categories.

- Increased understanding of international and cultural issues: In what way(s) do you have a better understanding of the country and culture where you studied abroad?

- Increased flexibility: How did you demonstrate flexibility, tolerance, or a positive attitude in adapting to differences abroad?

- Increased open-mindedness and curiosity: In what way(s) were your values tested, and what did you learn about your host culture's values?

- Enhanced critical skills: What new skills did you develop? In what way(s) did you develop a sense of accomplishment or an ability to be self-reliant?

Photos are judged on both the uniqueness of the photo and the relevance of the accompanying explanation to the learning outcome category. Our results have shown that accompanying explanations offer an insight into student learning and growth while abroad. Winning photos and accompanying descriptions by students have a prominent place on the TCU Center for International Programs website. Please see: http://studyabroad.tcu.edu/default. asp? pid $=135 \&$ cat $=$ Photos $)$

\section{Application of Model}

While the focus of this paper is to present a model for multidimensional assessment, it is worth noting some results in order to demonstrate the effectiveness of the Reflective Model of Intercultural Competence. Examples of 
qualitative data from each of the four learning outcomes are presented to demonstrate knowledge gleaned from the assessment process.

\section{Increased Understanding of International and Cultural Issues}

Students have much to say in their program evaluations regarding what they learned about their host country and culture. They often mention that they have a better understanding of their hosts, their habits, traits, values, or lifestyles, and could now better explain and defend them to Americans. Some comment on overcoming their stereotypes of locals, and coming to appreciate and wanting to adopt the local lifestyle, even after returning to the U.S. Many note they have a better understanding of how their country views the U.S. Many students are also able to articulate specific knowledge of the local politics, social, environmental, and historical issues, and other factors that affect their hosts. Some representative answers from program evaluations provide examples: (NB: student comments are unedited).

I feel that I have a better understanding of British people and their culture in general. Through the media, I came to better understand their politics. Our site visits in the medical community really helped me to understand their system of socialized medicine which also closely related to information about their economy. It was wonderful to learn so much about their culture! (and the differences taught me so much about mine!). — Summer 2007 London student.

I have learned about the transition of communism to capitalism in central European countries (how now to be successful you must have skills to offer; or you cannot find a job). — Summer 2007 Prague student.

I witnessed a culture that is more literate and values the arts more than we do. The English people are more reserved but also commit themselves deeply to the things that matter to them. I sampled what life in a large city is like and how the Brits deal with crowding - they have a strong sense of courtesy and a small sense of personal space. Summer 2006 London student.

"Understanding International and Cultural Issues" is also the most heavily entered category of the photo contest, and the photos and accompanying stories reveal insight into various cultural and international issues that the students are exposed to. 
Describing a photo of a man dressed in a thobe, a traditional Arabic robe, at Speaker's corner in Hyde Park, a student writes:

Londoners often take to parks when they have free time; lounging in the sun with a good book, or playing a game with their kids, whatever their activity, a park seems to be the perfect location for their needs. Speaker's Corner occurs on Sundays at Hyde Park, and this is an event that we knew we had to be a part of at least once in our stay abroad. This picture captures one particular speaker that caught my eye, who was speaking out about the differences in religious practices. He really opened my eyes to how simple it can be to state your mind to others, just because you want to and have the privilege to do so. You don't have to be hostile or resentful, and if you are open to arguments, then the public will show respect and be open to what you have to say.

[For this student photo, please visit: http://studyabroad.tcu.edu/default.as p?pid $=199 \&$ cat $=$ Photos\#Understanding $]$

Describing a photo of three old men with their backs to the camera, standing looking over a railing at a valley below, a Spring 2007 Spain student writes:

One weekend, I traveled to a small town called Arcos de la Frontera, one of the famous Pueblos Blancos in the south of Spain, which features narrow streets and whitewashed buildings. One lazy Sunday afternoon, I took a walk to the end of town, where I saw one of the most amazing views I had ever seen. The city is situated on the edge of a cliff, and looks over a gorgeous valley. What made this view so special, however, was a gathering of elderly Spanish men-something, it seemed, they did quite often. As they looked over the railing, they discussed the weather, food, their family lives, and so on. I realized that they were not there for the view, but for companionship, entertainment, and gossip. I learned that day that no matter where you are or where you come from, no matter your environment, everyone needs their friends.

In sum, when explicitly asked what they learned about their host country and culture, students stated clearly that they have gained cultural and global awareness, through increased knowledge of their host culture's values, views, and perspectives. Furthermore, many feel it gave them more awareness and empathy for different cultures in general. Some also mention that their experiences opened their eyes to what they did not know, and gave them a desire to become more globally aware. 


\section{Increased Flexibility}

In their program evaluations, students have no shortage of items to discuss regarding how they developed flexibility and tolerance. Many comment that cultural differences were problematic at first but came to be appreciated. Some of the issues mentioned include having to adjust to local food and dietary practices, using public transportation or walking, adjusting to smaller spaces, living in different accommodations with different amenities, adjusting to differences in customary practices or orientation to time, and learning a new language or conversational style. A few commented on issues related to the group dynamics of their U.S. peers. Some representative answers from program evaluations follow:

Everything on this trip required us to be flexible and adventurous but that is so important especially for Americans. We have gotten so comfortable in our suburban homes and air-conditioned offices and classrooms. The whole point of the trip is to put you outside your comfort zone and give you a complete experience of life in another country. — Summer 2006 Budapest student

Before going to any foreign speaking country, I now know that it is IMPERATIVE to know some of the language. 10 phrases would have gotten us really far. — Summer 2007 Italy student.

I developed tolerance to the Mexican value of time. Being on time does not matter so much and the days in general are more relaxed and laid back. I really enjoyed this aspect of the culture. — Summer 2006 Mexico student.

The category "Increased Flexibility" is typically the least entered in the photo contest, perhaps due to the difficulty of trying to find a photo to portray students' experiences and growth. Nonetheless, the entries we do receive are quite compelling. A Spring 2007 Spain student describing a photo of a matador raising his sword as a bull charges towards him writes:

At the beginning of April my friends and I went to the first bullfight of the season. Before we purchased tickets I did not want to go, and even during the first fight I hid my eyes so as not to see an innocent animal being killed. After a few minutes of being in the ring my feelings began to change. I looked around and noticed that everyone from grandmothers to small children were in awe of the grace and technique the matadors possessed. I pictured a bullfight to be a loud rucas of blood and gore, but it 
was quite the opposite. The audience was silent as they watched with the utmost attention and clapped when the bullfighters showed exceptional skill. I slowly became more accepting of this tradtion and even enjoyed watching the festivities by the end. I left the ring have much more appreciation for this sport and realized I could adapt to almost any tradition after that afternoon.

[For the student photo, please visit: http://studyabroad.tcu.edu/default.as p? pid $=199 \&$ cat $=$ Photos $\#$ Flexibility

Overall, students show maturity and awareness as they deal with differences. Furthermore, many express pride at their ability to adapt to different lifestyles, customs, habits, and norms, and note that study abroad has given them confidence to adapt to future situations.

\section{Increased Open-mindedness and Curiosity}

In the program evaluations, when asked about how they were exposed to new values or had to think about their own, students generally remark on differences in political opinions. Many students indicate they felt outright criticized about U.S. political issues while abroad, but some note that it was an eye-opening experience to see how others feel and to learn others' perspectives. Others note that such interactions are an opportunity to show that not all Americans feel the same way, or a chance to defend their beliefs.

Some responses demonstrate an awareness about differences in materialism, indulgence and self-centeredness. These responses were either observations the students made about the differences in between from the U.S. and the host country, showing perceptiveness and introspection, or remarks about having been criticized for U.S. values. For example:

I found that Europeans don't care as much about material things. They value experience and family above money and other material things. Summer 2006 Italy student.

Lots of critiques about the food and how much the U.S. overindulges. Summer 2006 Germany student.

I found it amusing during the whole trip that we were walking around as loud, obnoxious Americans, fitting the profile very well. — Summer 2006 London student. 
A few comments showed a remarkable level of maturity and curiosity to engage in friendly debates and learn from the locals. For example:

At Speaker's Corner in London, I was challenged with a speaker who held vastly different views than I did about racial equality. After talking with him though, on a one-on-one basis, I came to the realization that he was merely human, and no more or less obliged to his opinion than I am, and in that respect, no more right or wrong than I am about my opinions in this world. It brought into perspective our equality as a human race for me. - Summer 2007 London student

After visiting the Hiroshima Peace museum I felt so guilty to be American. Not due to the bombing, that was sad, but due to the current efforts we (America) are taking to stop that type of destruction from occurring again. America is one of the leading nuclear warfare manufacturers. I realized I have to take a more active role in preventing nuclear warfare and portraying peace. Talking to my classmates, we all felt the same way. Also, I spoke to the students and the university in Japan our age and they do not express any remorse towards us because we are American. They portray peace and forgiveness. I was overwhelmed by their maturity and forgiveness. - Summer 2007 Japan student

I was talking to the bell boy about politics, and it really made me question what I believe. It's a good feeling when you are questioned, because it makes you want to dig deeper and discover your own beliefs and passions in life. I never was interested in politics ... Now I can't stop watching CNN or digging into the news paper. — Summer 2006 Italy student.

The photo contest entries for the category "Increased Open-mindedness and Curiosity" are always very revealing. For example, a Summer 2008 London student describes a wall-sized photo mural outside a museum:

This picture was taken in front of the Tate Modern Art Museum in London. At first glance you think it is a black man with a gun in his hand aimed and ready to fire. At closer inspection you realize that it is not a gun, but a video camera. The intense and aggressive picture forces us to re-evaluate our assumptions and teaches us to counteract pessimistic stereotypes. With no words at all this picture is a perfect example of the false impression many countries have on one another. Going to study abroad, I was warned that the people of London were rude and have a negative 
outlook on Americas. After getting to know a handful of Londoners I was so surprised how false everything I heard was, just as they were surprised to be proven wrong on their previous views of Americans. I was shown, just as this picture portrays, that you cannot judge a person on impressions or stereotypes that have previously been formed. You must look closely at the culture just as you must look closely at this picture to be able to see what it truly is. Looking closer into their culture I found that London is a place of so much interesting history and full of people who are proud of what their country represents and the tradition it carries.

[For the student photo, please visit: http://studyabroad.tcu.edu/default. asp? pid $=217 \&$ cat $=$ Photos $\#$ Values $]$

This section, more than any other, seems to reveal the differences in growth and development among students. While some are unwilling or unable to move away from defensiveness, others show a great deal of openness, learning, and introspection.

\section{Enhanced Critical Skills}

Students repeatedly write in their program evaluations that they feel a sense of accomplishment in having learned about life abroad and having succeeded in a foreign city on their own. For many, this was the first time to travel without their family; others, did not know the other students on the program ahead of time. so greater self-reliance was needed. Many students mention feeling more independent and self-reliant as they traveled alone within the city, learned how to navigate public transportation, and found their way when lost.

Students also find that trying to communicate in a foreign language requires resourcefulness, such as using non-verbal gestures, rephrasing, and carrying a dictionary. They mention humility about their lack of language skills, appreciation for those who are trying to learn a new language, and confidence in their own skills and ability to learn.

Students enumerate many other situations that required new skills, such as learning how to budget, dealing with lost or stolen credit cards, learning how to bargain, learning to be less wasteful, to connect with the locals, to become a group leader, and in general learning to become more independent. The answers are quite revealing as to students' own perception of their growth. For example:

I really learned the importance of working well in a group and allowing others to take charge in addition to not being afraid to take charge. I got lost 
a couple of times when I ventured out by myself, and I learned to stay calm and take time and I always found my way. Dealing with language barriers while traveling out of London showed me we're all very similar even if we speak a different language and it's important to realize that the whole world doesn't speak English and it's not always everyone's job to yield to me and what I'm used to. While in another country, it's my job to yield and adapt to that culture, not the other way around! — Summer 2007 London student.

Overall I learned how to be patient. I learned how to be patient making phone calls, speaking with other people when I could not understand them, getting around the city, being in close proximity with other people. Patience will be valuable to me as I enter a career. — Summer 2006 London student.

I think more than anything I just learned to constantly be aware of and SENSITIVE TO my surroundings. Before, I had the tendency to race through things in a very loud, quick, and demanding way. Now, I stop, listen, and assess the situation before acting. — Summer 2006 London student.

I think people skills and problem solving skills are required in every situation when you travel. Even something as simple as buying a bus ticket or trying to figure out the train schedule involves people skills and problem solving skills! These are both skills that I think develop throughout your whole life, and traveling is one of the best things for that! - Summer 2006 London student.

Likewise, the photo contest entrants in category "Enhanced Critical Skills" show students pushing their limits, thriving in their new setting, and transforming into capable, talented adults. Discussing a photo of himself at a chalkboard in a schoolroom, a Summer 2007 Dominican Republic student writes:

This photo shows just one aspect of my volunteer work while abroad in the Dominican Republic. Every day for one month, I and one other American were in charge of 50 Dominican children with unstable home lives. Here, I can be seen teaching the children the basics of English. Although resources and help were scarce, overcoming these challenges and watching the children learn presented me with a unique sense of accomplishment that I will be able to carry with me for the rest of my life. While I know that most of the kids will probably forget me as time goes by, I hope that I have at least left a lasting impression on them. 
[For the student photo, please visit: http://studyabroad.tcu.edu/default.as p? pid $=199 \&$ cat $=$ Photos\#Understanding

A Summer 2007 London Student writes of a photo of him and a fellow student consulting a map and a guidebook

This picture was taken in Hyde Park, which is a located in Central London, and is one of the Royal Parks of London. Still in the beginning weeks of our time abroad, we had stopped in the park for some time to journal, take in the park life, and decide where we would be heading off to next on our afternoon off. This picture perfectly depicts a common activity for our group; much time was spent scouring the city maps as we figured out how to get to where we wanted to go. In the beginning of the trip, we were unfamiliar with the city, and relied heavily on our maps to help us get around. Despite this, there were still times that we got lost, turned around, showed up late somewhere, all because we didn't know where we were going. By the end of the trip though, we had found the happy medium that exists between dependence on a map and our own intuition. We even happily accepted new adventures and destinations so that we could explore and remind ourselves that we can be independent, and survive on our own in foreign places.

This picture is a constant reminder of our accomplishments, and also of the fun that can be had even when things don't go quite as planned.

[For the student photo, please visit: http://studyabroad.tcu.edu/default.as p?pid $+199 \&$ cat + Photos\#Flexibility

For many students studying abroad gave them increased independence and self-confidence. Overall, the responses and photos reveal the development of many valuable and lifelong skills from studying abroad.

\section{Utilizing the Findings}

The data collected from the student evaluations and photo contests are used in a number of ways: to promote study abroad, to assist in pre-departure orientation, and in program assessment. The data is also utilized to demonstrate to faculty, staff, and administration the importance of study abroad.

\section{Marketing}

The winning photos and explanations from the photo contest are enlarged, matted, and displayed on a "traveling exhibition" in several buildings across 
campus. We find that winners bring their friends to show them their photos, and many students, faculty, and staff stop to view them. We have been overwhelmed by the positive response to the exhibition, and in particular to the stories. The photo exhibition and accompanying stories generates discussion on campus and with former and prospective study abroad students about the unique, tangible, lifelong outcomes of studying abroad.

We use the winning photos to create various marketing materials, including bookmarks and banners. In addition, the photo contest winners are displayed on our website, by category, and in the quarterly university magazine. We also select some particularly striking or representative quotes from the photo contest and the evaluations to use in power point slideshows and on our website (see: http://studyabroad.tcu.edu/default.asp?pid=210\&cat=Photos ).

\section{Pre-departure information}

Another use of the data collected from the evaluations and photo contests is in our pre-departure information. Comments that appear again and again, or comments which are of the "I wish I had learned earlier" genre are used in pre-departure handbooks and orientations to alert students as to what to expect while they are abroad or to help them make the most of their experience. In addition, students are given information about the photo contest and categories before they go and while they are abroad, to plant seeds about framing what they are learning. In these ways, both the categories of learning outcomes and the actual learning are shared with students before they go as advice.

\section{Office assessment}

Finally, the data collected is used in our annual office assessment report, to document how we are or are not reaching our goals. The report indicates the overall response rate in the evaluations and the percentage of answers which demonstrate students are able to articulate the learning outcomes. The response rate on evaluations is typically $50 \%$ response rate, and of those evaluations, $75-85 \%$ of the responses meet our criteria. Answers which do not meet our criteria are those which reflect no learning or development (i.e., no, not really, I can't think of anything like this, from a Summer 2007 London student) or those in which the student gives an answer which does not appear to demonstrate learning (i.e., "I now understand why people have certain stereotypes about the French," from a Summer 2007 France student).

Based on the data collected to date, we have formulated several strategies to help more students achieve the learning outcomes. We have created an online 
orientation about health and safety issues for all students, which will enable pre-departure meetings to be more focused on cultural learning, culture shock, and other intercultural issues. We are considering creating an online course for students while they are abroad. The course would have readings related to our outcomes, and assignments for students to engage their local community actively. As an alternative to the online course, we have also discussed other incentives for students to increase students' community engagement while abroad. In addition, we may implement journaling questions related to our outcomes, to increase students reflective journaling while abroad.

\section{Conclusion}

This research demonstrates how an intentional approach to student learning outcomes can help students achieve and articulate those outcomes. Qualitative data can be collected from both student evaluations and other sources, such as photo contests, in order to measure how students are achieving the outcomes.

While the idea of reading open-ended answers to five questions of hundreds of surveys each year can seem daunting, it is in fact an invigorating experience. For study abroad administrators who are not able to be on site while students are learning, the opportunity to read about their experiences and see their transformation provides a great deal of satisfaction. Most importantly, this approach also provides the students with a valuable tool for framing their experiences in their own mind, and for future discussion with parents, employers, and friends.

The Reflective Model of Intercultural Competence uses multidimensional open-ended questions to gather data about student learning and to encourage student reflection. Future uses of the model could include comparisons of results between program types, program lengths, and program locations, as well as longitudinal studies.

Encouraging students to reflect on their experiences abroad and to articulate their own outcomes, shows that students gain intercultural competence and the ability to articulate it, through specific instances and examples. By giving students multiple methods for reflection, this model provides opportunities for students with different learning styles to reflect on and articulate their experiences from studying abroad. Such a model provides an innovative and significant approach to outcome assessment for study abroad. 


\section{References}

Brislin, R. \& Yoshida, T. (1994). Intercultural communication training: An introduction. Thousand Oaks, CA: Sage Publications.

Chieffo, Lisa and Lesa Griffiths. (Fall 2004). "Large scale assessment of student attitudes after a short-term study abroad program." Frontiers: The Interdisciplinary Journal of Study Abroad, 10, 165-177.

Deardorff, D. K. (2004). The Identification and Assessment of Intercultural Competence as a Student Outcome of Internationalization at Institutions of Higher Education in the United States. Doctoral dissertation. Raleigh, NC: North Carolina State University.

Dignes, N. (1983). "Intercultural competence.” In D. Landis \& R. W. Brislin (Eds.), Handbook of intercultural training, volume 1. Elmsford, NY: Pergamon Press, Inc.

Grunzweig, W. \& Rinehart, N. (1998). "International Understanding and Global Interdependence: A philosophical inquiry.” International Educator, Fall, 41-48.

Gudykunst, W. (1991). Bridging Differences: Effective Intergroup Interactions. Newbury Park, CA: Sage Publications.

Gudykunst, W., Ting-Toomey, S. \& Wiseman, R. (1991). "Taming the Beast: Designing a course in intercultural communication. Communication Education, 40, 272-285.

Ingraham, Edward C. and Debra L. Peterson (Fall 2004). "Assessing the impact of study abroad on student learning at Michigan State University." Frontiers: The Interdisciplinary Journal of Study Abroad, 10, 83-100.

Jackson, J. (August, 2005). "Assessing intercultural learning through introspective accounts." .Frontiers: The Interdisciplinary Journal of Study Abroad, $11,165-186$.

Kehl, K. and J. Morris (Winter 2007-2008). "Differences in global-mindedness between short-term and semester-long study abroad participants at selected universities." Frontiers: The Interdisciplinary Journal of Study Abroad, 15, 67-79.

Kelley, C., \& Meyers, J. (1995). CCAI Cross Cultural Adaptability Inventory Manual. Minneapolis, MN: National Computer Systems, Inc.

Kim, Y. (1991). "Intercultural communication competence: A systems-theoretic view." In S. Ting-Toomey \& F. Korzenny (Eds.) Cross-cultural interpersonal communication (pp.259-275). Newbury Park: Sage Publications.

Ogden, A. (Fall, 2006). Ethnographic inquiry: Reframing the learning core of education abroad. Frontiers: The Interdisciplinary Journal of Study Abroad, $13,87-12$. 
Olson, C. L., \& Kroeger, K. R. (Summer 2001). "Global competency and intercultural sensitivity." Journal of Studies in International Education, 5, 116-137.

Sutton, R. \& D. Rubin. (Fall 2004). "The GLOSSARI project: Initial findings from a system-wide research initiative on study abroad learning outcomes." Frontiers: The Interdisciplinary Journal of Study Abroad, 10, 65-82.

Ting-Toomey, S. (1999). Communicating Across Cultures. New York: The Guilford Press. 